\title{
Implicações do contexto digital no ensino de línguas adicionais na era da cibercultura
}

\author{
Aline Almira Morbach ${ }^{\mathrm{i}}$ \\ Maruana Kássia Tischer Seraglio ${ }^{\text {ii }}$
}

\section{RESUMO}

Observando o contexto cibercultural no qual vivemos nos dias atuais, a presente pesquisa visa a discutir as implicações do contexto digital no ensino de línguas adicionais para adolescentes, buscando um melhor entendimento acerca da influência dos recursos digitais no processo de ensino-aprendizagem. Para tanto, analisou-se o discurso de professores de línguas adicionais, com foco no público adolescente, de escolas públicas e privadas e de idiomas da região Oeste de Santa Catarina, utilizandose o aporte metodológico da Análise de Discurso. As análises demonstraram que professores de línguas adicionais encontram-se adaptados à utilização de recursos digitais em aula, vendo-a como benéfica e favorável ao aprendizado da língua-alvo. Além disso, verificou-se que grande parte dos professores estimula o uso de recursos digitais com foco educacional extraclasse.

Palavras-chave: Contexto Digital; Ensino de Línguas Adicionais; Tecnologia; Cibercultura.

\begin{abstract}
Observing the cybercultural context in which we live today, this research aims to discuss the implications of the digital context in teaching additional languages to teenagers, seeking a better understanding of the influence digital resources have in the teaching-learning process. In order to achieve this goal, additional languages teachers from public, private, and language schools in the West of Santa Catarina had their speeches analyzed using the methodological contributions of the Discourse Analysis. The analysis showed that additional language teachers are adapted to the use of digital resources in class and see it as positive and favorable to the learning of the target language. In addition, it was found that most teachers encourage the use of digital resources as an extra class educational resource.
\end{abstract}

Keywords: Digital Context; Additional Languages Teaching; Technology; Cyberculture.

\footnotetext{
${ }^{i}$ Mestranda em Estudos Linguísticos - UFFS

https://orcid.org/0000-0002-4414-5856 | aline.morbach@estudante.uffs.edu.br

ii Mestranda em Estudos Linguísticos - UFFS

http://orcid.org/0000-0002-0751-3445 | maruana.seraglio@estudante.uffs.edu.br
} 


\section{INTRODUÇÃO}

Nas décadas recentes, o sistema educacional tem sido pressionado pela tecnologia e sua revolução voltada ao dinamismo e à transformação dos antigos hábitos operacionais. Mesmo assim, devido a diversos aspectos, como a falta de estrutura física nas instituições ou de formação profissional para educadores manusearem essas tecnologias, se vinha realizando um movimento constante de rejeição do contexto digital no ensino, que, com o passar do tempo, foi alterando-se com a inserção e a normalização das tecnologias. Vivemos na era da pós-modernidade, a qual Bauman (1998) caracteriza como a impossibilidade de permanecer fixo, estando em constante movimento, ou seja, as incertezas do sujeito pós-moderno são “concentradas na identidade individual, em sua construção nunca completa e em seu sempre tentado desmantelamento com o fim de reconstruir-se" (BAUMAN, 1998, p. 221, grifos no original). Transpondo isso para o campo educacional, entendemos que a busca contínua por novas abordagens e recursos permite ao professor ensinar de modo mais contextualizado e atrativo, principalmente no ensino voltado para adolescentes, que estão em contato frequente com os meios tecnológicos.

A partir disso, esta pesquisa se justifica pela importância em se compreender os impactos do contexto digital no ensino de línguas adicionais para adolescentes, visto que, como dito anteriormente, estes são os mais conectados à tecnologia, nesta era de cibercultura na qual nos vemos imersos. Assim, buscamos responder à pergunta: como os professores lidam com o contexto digital no ensino de línguas adicionais para adolescentes em escolas públicas, em escolas privadas e em escolas de idiomas?

Buscando responder a esse questionamento, o objetivo geral desta pesquisa é discutir as implicações do contexto digital a partir das perspectivas de professores de línguas adicionais para adolescentes na era da cibercultura. A partir dessa finalidade, propomos três objetivos específicos: (1) realizar um levantamento teórico sobre o ensino no contexto digital; (2) analisar o discurso de professores de línguas adicionais no que tange às implicações do contexto digital no ensino, considerando suas perspectivas sobre as vantagens e as desvantagens do uso desse contexto; e (3) investigar quais os impactos do contexto digital no desempenho dos alunos em sua língua-alvo, a partir dos discursos dos professores participantes. 
O aporte metodológico é fundamentado na Análise de Discurso (doravante AD) francesa, utilizada como mecanismo de diálogo entre o aporte teórico construído e as análises dos dados, os quais foram coletados na região Oeste de Santa Catarina. Ademais, a pesquisa se desenvolve em momentos: primeiramente ocorre levantamento teórico sobre o ensino na era da cibercultura; em seguida explana-se sobre a metodologia utilizada, bem como apresentação dos participantes e do processo de coleta de dados; depois são feitas as análises e as discussões a partir dos discursos dos professores participantes; e, por fim, reflete-se sobre os estudos realizados e os resultados alcançados, além das implicações e da importância do tema para futuras pesquisas.

\section{ENSINO NA ERA DA CIBERCULTURA}

Vivemos em um contexto cibercultural no qual as relações tecnológicas imperam, e mais que uma simples modernização dos aparelhos que utilizamos ou passamos a utilizar, vemo-nos imbuídos em uma rede de acontecimentos e de saberes, não sendo mais possível identificar as fontes primárias do muito que ouvimos, que vivemos ou a que somos expostos. Lévy (1999), referindo-se à cibercultura, explana que a essência da cultura humana se vê modificada, sem fronteiras e limites, trazendo um conceito de universalidade, de criação coletiva, de comunidade global. Nessa mesma perspectiva, Champangnatte e Cavalcanti (2015) veem a cibercultura como uma modalidade sociocultural de configuração das comunidades, considerando que "o ciberespaço emerge como um território sem fronteiras, aparentemente sem controles e hierarquias, em que não há pontos fixos e nem lineares para a disseminação de informações" (CHAMPANGNATTE; CAVALCANTI, 2015, p. 314). Para Lemos (2005, p. 2), “o desenvolvimento da cibercultura se dá com o surgimento da microinformática nos anos 70, com a convergência tecnológica e o estabelecimento do personal computer (PC)", sendo este um cenário de constante evolução desde então.

Nesse contexto cibercultural, enquanto somos bombardeados por diversos tipos de informações vindas de diversas fontes, buscamos uma atualização constante, além de um certo domínio dos recursos tecnológicos que nos cercam. Estamos a todo momento conectados à tecnologias nômades, como smartphones, tablets e notebooks (LEMOS, 
2005), acessando redes sociais, compartilhando, curtindo, seguindo; pesquisando sites confiáveis para estudo e construção do conhecimento; disseminando e popularizando o acesso à pesquisa. Podemos destacar outras práticas digitais que nos rodeiam no cotidiano, como ressaltam Anjos-Santos et al. (2014, p. 84-85):

\begin{abstract}
[...] enviar e-mails; acessar o facebook e responder mensagens de amigos, comentar em fotos, compartilhar vídeos e fotos com legendas diversas; assistir e/ou postar um vídeo no youtube e reagir às postagens que apreciam os diferentes vídeos do youtube; buscar informações em fóruns sobre como realizar determinada atividade; ler e avaliar a opinião de diferentes consumidores na web sobre produtos que queremos adquirir; reclamar e protestar contra danos causados ao consumidor nos sites da empresa fornecedora do produto; acompanhar e solicitar informações de órgãos governamentais sobre os gastos públicos de determinada área/setor são algumas das muitas ações sociais que podemos realizar [...].
\end{abstract}

Esta abundância de informações contribui para a constituição do sujeito pósmoderno, fragmentado (BAUMAN, 1988), ademais, é preciso pensar que os meios tecnológicos e de comunicação contribuem para a interpelação do indivíduo em sujeito, como caracterizado por Pêcheux (2014), afinal, diversas ideologias circulam nesses espaços e interpelam o sujeito, evidenciando a importância de um olhar crítico sobre essas informações. Além disso, na $\mathrm{AD}$, entende-se o corpus de análise produzido não apenas pelo sujeito, mas relacionado com a sua posição sócio-histórica. Segundo Foucault (2017), devemos perguntar como determinado enunciado apareceu e não outro, sendo preciso descobrir o não dito dentro desse discurso, ou seja, se trata:

\footnotetext{
De compreender o enunciado na estreiteza e singularidade de sua situação, de determinar as condições de sua existência, de fixar seus limites da forma mais justa, de estabelecer suas correlações com os outros enunciados, a que pode estar ligado, demonstrar que outras formas de enunciação excluem (FOUCAULT, 2017, p. 34).
}

Nesse sentido, percebemos que os discursos são atravessados por questões sociais e históricas que devem ser levadas em consideração (MAINGUENEAU, 1997). Desse modo, o sentido desliza no não dito, pois o sentido não está ligado à palavra em si, à sua literalidade. É a partir da transferência de sentidos "que elementos significantes passam a se confrontar, de modo que se revestem de um sentido" (ORLANDI, 2015, p. 42). Assim, é preciso um olhar crítico sobre os contextos digitais e os sentidos que circulam nesses espaços, visto que, segundo Lévy (1999), a cada minuto novas informações são acrescentadas no ciberespaço, definido por ele como "o espaço de comunicação aberto pela interconexão mundial dos computadores e das memórias dos 
computadores" (LÉVY, 1999, p. 92). Devido a essa quantidade imensa de informações, o ciberespaço é universal e se altera sempre, e a cibercultura aceita todos os conteúdos ali inseridos, não se importando com os sentidos relacionados.

No que tange à educação, o surgimento das tecnologias e suas constantes transformações levam Gebran (2009) a afirmar que vivemos em uma Era da Informação, posto que "todas essas mudanças no âmbito da sociedade fazem com que a escola repense seus mecanismos de ensino que acompanhe o ritmo das novas gerações cada dia mais tecnológicas (sic)" (CASSIANO, 2019, p. 17). Logo, os processos de ensino-aprendizagem envolvem novos aspectos temporais, espaciais e comunicacionais, sendo impossível "dissociar o indivíduo das tecnologias que estão a cada dia mais próximas de sua realidade" (CASSIANO, 2019, p. 17).

Dentro desse contexto digital da vida cotidiana, como apontam Carvalho e Carvalho (2020), estudantes dispõem de acesso gratuito a materiais de estudo e informações com maior facilidade atualmente, posto que a facilidade de conexão permite a popularização desses recursos digitais. Os autores ainda ressaltam a pertinência desses recursos digitais no processo educativo, considerando que a presença da tecnologia já se tornou intrínseca ao cotidiano dos aprendizes, a qual pode trazer benefícios ao processo de ensino-aprendizagem, levando os alunos a uma apropriação desses recursos para estudo extraclasse, o que incita a autonomia.

Ainda assim, é necessário levar em consideração, a nível de país, o número de brasileiros que dispõe de acesso à internet em casa. Segundo dados do Instituto Brasileiro de Geografia e Estatística (IBGE), 79,1\% dos lares brasileiros tinham acesso domiciliar à internet no ano de 2018, sendo o maior número concentrado em áreas urbanas, com 79,4\%, contra apenas 46,5\% na área rural. Já a região Sul do Brasil, local onde está inserida a presente pesquisa, $81,1 \%$ dos lares contavam com a utilização da internet no ano de 2018, ficando atrás apenas da região Centro-Oeste, com 83,5\% (BRASIL, 2018). Por isso, precisamos refletir sobre os sujeitos que não têm acesso a esses meios tecnológicos ou, quando o tem, é de modo eventual; logo, a utilização da tecnologia deve ser pensada e utilizada de acordo com a realidade específica daquele espaço, para que a dificuldade de acesso não seja um fator prejudicial à aprendizagem do aluno. 
Sobre os benefícios no processo de ensino-aprendizagem, Lévy (1999) destaca que as tecnologias encontradas no ciberespaço ampliam e modificam funções cognitivas como a memória, a imaginação e o raciocínio. Ademais, as tecnologias oferecem:

novas formas de acesso à informação [...], novos estilos de raciocínio e de
conhecimento, tais como a simulação, verdadeira industrialização da
experiência do pensamento, que não advém nem da dedução lógica nem da
indução a partir da experiência (LÉVY, 1999, p. 156).

O autor também reflete sobre a manutenção das práticas pedagógicas, com esse formato de transação de conhecimento, sendo este um momento de crítica e de reflexão aos modelos até então vigentes, incluindo os papéis de professor e aluno (LÉVY, 1999).

Nesse sentido, Prensky (2001) trata da Era Digital, dentro do campo educacional, na qual, em sua concepção, existem dois sujeitos: o aluno identificado como nativo digital e o professor enquanto imigrante digital. Essa noção é construída por se entender que os estudantes (com idade escolar) são "falantes nativos da linguagem digital dos computadores, dos vídeos games e da Internet" (PRENSKY, 2001, p. 1, tradução nossa), ou seja, esses alunos possuem interesse e conhecimentos sobre a tecnologia, pois essa geração cresceu rodeada de aparatos tecnológicos, aprendendo desde criança a utilizá-los. O autor complementa que "os alunos de hoje não são mais as pessoas para as quais nosso sistema educacional foi projetado" (PRENSKY, 2001, p. 1, tradução nossa). Posto isso, entendemos que os sistemas educacionais estariam de certo modo ultrapassados ao não acompanharem essas mudanças. Rodrigues et al. (2017) ressaltam ainda que seria um erro desprezar o conhecimento que essa geração possui e todos os recursos proporcionados por esse universo tecnológico, assim, "precisamos aprender a utilizá-la em nosso favor, como uma ferramenta para auxiliar no processo de ensino e aprendizagem" (RODRIGUES et al. 2017, p. 22).

Desse modo, “inovações nas práticas educativas são fundamentais devido à transformação contínua da sociedade" (KAIRALLAH, 2018, p. 5). Portanto, é preciso que se reflita sobre novas abordagens que estimulem o interesse e as habilidades dos alunos, ressignificando modelos de aprendizado e de ensino tradicionais que se adaptem às realidades e necessidades de educadores e de educandos. Afinal, de acordo com Lévy (1999, p. 156), "pela primeira vez na história da humanidade, a maioria das competências adquiridas por uma pessoa no início de seu percurso profissional estarão obsoletas no fim de sua carreira", ou seja, deve-se refletir sobre os movimentos que envolvem o saber e suas transformações ao longo do tempo. 
Além disso, Cassiano (2009, p. 17) ressalta que o professor tem o compromisso de refletir sobre sua própria prática pedagógica, afinal, "suas ações devem ser sobretudo planejadas que considere a associação da tecnologia ao conteúdo trabalhado, uma vez que o uso errôneo da tecnologia em sala de aula pode influenciar negativamente o aluno (sic)". Contudo, o uso correto ou incorreto das tecnologias no processo de ensino não exclui o papel do professor como facilitador ou mediador do aprendizado.

Como assevera Lévy (1999), a principal ferramenta para acesso aos mais diversos conhecimentos no mundo é a Internet e os professores precisam estar atentos, aproximando seus alunos desse universo de conhecimentos, aprendendo a utilizar da melhor maneira possível esses recursos, tornando as aulas e a aprendizagem mais prazerosas, críticas e úteis ao aprendiz. Lévy (1999, p. 170) ainda diz que a “aprendizagem a distância foi durante muito tempo o 'estepe' do ensino; em breve irá tornar-se, senão a norma, ao menos a ponta de lança", como podemos acompanhar a evolução do ensino a distância, no atual contexto em que vivemos.

Frente a esse contexto digital cada vez mais presente na vida cotidiana, é preciso refletir sobre as práticas tradicionais de ensino e buscar novas formas de ensinar e de aprender, colocando em movimento a produção de conhecimento. É importante pensar que o sistema tradicional de ensino, muitas vezes, é um processo de ensino ditatorial. Sobre esse tema, Orlandi (1987) discute sobre o que ela denomina como Discurso Pedagógico, caracterizado como um discurso autoritário e que muitas vezes é o modelo de discurso seguido nas instituições de ensino. Para Paiva (2019, p. 22), "cada vez mais, vamos ser demandados a nos fazer presentes em camadas digitais sobrepostas à estrutura física e alterar nossas ações de linguagem entre elas sem perder o foco de nenhuma delas". Ainda sobre isso, Lévy (1999, p. 170) complementa que "os indivíduos toleram cada vez menos seguir cursos uniformes ou rígidos que não correspondem a suas necessidades reais e à especificidade de seu trajeto de vida", logo, buscam por outros métodos de ensino que se distanciam do modelo tradicional, sendo o universo da cibercultura uma alternativa.

\section{METODOLOGIA}


Esta investigação se enquadra enquanto pesquisa qualitativa e tem como alicerce metodológico a AD. Assim, propomos pensar as respostas dos participantes enquanto discurso, no sentido utilizado por Maingueneau (2015, p. 36), pois “as pessoas produzem textos para fazer passar uma mensagem, para exprimir ideias e crenças, para explicar algo, para levar outras pessoas a fazer certas coisas ou a pensar de certa maneira, e assim por diante". Desse modo, o sentido não é construído dentro das fronteiras do discurso, mas mobilizando elementos exteriores, ou seja, o contexto externo ao dizer do professor influencia e se mostra no discurso.

Os participantes desta pesquisa são professores(as) que lecionam línguas adicionais para adolescentes em escolas públicas, em escolas privadas ou em escolas de idiomas localizadas na região Oeste de Santa Catarina. As línguas adicionais lecionadas pelos participantes envolvem língua inglesa, língua espanhola, língua francesa e língua alemã, sendo cada uma dessas línguas representada por 2 entrevistados, totalizando 8 participantes. Destes, seis são do sexo feminino e dois do sexo masculino, com idades entre 21 anos e 54 anos. Os participantes possuem de 1 até 34 anos de experiência no ensino das respectivas línguas.

Para coleta de dados, foi desenvolvido um questionário por meio da plataforma digital gratuita Google Forms. O formulário foi enviado aos participantes em 24 de julho de 2020 e todas as respostas foram obtidas até 07 de agosto de 2020. As questões que constituíram o questionário foram: a) Levando em consideração a Era digital em que vivemos, na qual alunos têm acesso a aplicativos de idiomas, a tutoriais do Youtube, a músicas e séries na língua-alvo, quais as vantagens e quais as desvantagens do contexto digital externo à sala de aula no ensino do idioma? Explique; b) Você utiliza ferramentas tecnológicas em suas aulas (ex. filmes, séries, canais no Youtube, aplicativos, jogos, músicas, etc.)? Se sim, quais?; c) Você indica aos seus alunos recursos digitais para estudo (ex. filmes, séries, canais no Youtube, aplicativos, jogos, músicas, etc.)? Por quê?; d) Professor(a), você percebe que alunos interessados em recursos tecnológicos para estudos na língua-alvo apresentam um melhor desempenho com o idioma? Explique.

Os movimentos de análise ocorrem a partir dos discursos dos participantes sobre o contexto digital no ensino de línguas, enfatizando suas vantagens e desvantagens, uso de ferramentas tecnológicas no ensino e sua influência no desempenho da língua-alvo 
de seus alunos. Como os participantes são professores de diferentes línguas adicionais (foram dois para cada língua) e visando à melhor compreensão para o leitor, os discursos são identificados pela letra inicial de cada língua e a numeração do participante, sendo: Professor de Inglês (PI-1 e PI-2); Professor de Francês (PF-1 e PF2); Professor de Alemão (PA-1 e PA-2); e Professor de Espanhol (PE-1 e PE-2). Além disso, por tratarmos de recortes dos discursos desses participantes a partir do questionário, utilizamos Sequências Discursivas (SD), também enumeradas, que contêm as representações relevantes para as análises.

Mesmo com o estabelecimento do método de análise e delineamento de participantes, não se busca uma completude com relação ao tema, nem respostas certas e erradas ou julgamentos sobre a prática docente dos participantes. Assim, esta pesquisa se constitui em problematizar e fazer com que cada leitor possa, com as suas experiências e suas formações (nunca completas), continuar buscando e encontrando novos significados para o que for aqui exposto.

\section{ANÁLISES E DISCUSSÕES SOBRE O CONTEXTO DIGITAL NO ENSINO DE LÍNGUAS ADICIONAIS}

\subsection{Vantagens e Desvantagens}

De acordo com Santos (2012, p. 27), "o indivíduo na condição pós-moderna é um sujeito blip [fragmentado, retalhado], alguém submetido a um bombardeio maciço e aleatório de informações parceladas que nunca formam um todo". Assim, pensando no contexto digital em que nos vemos inseridos, no qual a tecnologia já é constituinte do sujeito pós-moderno, principalmente na vida cotidiana dos adolescentes que têm acesso a aplicativos de idiomas, a tutoriais do Youtube, a músicas e séries na língua-alvo, perguntamos aos professores quais as vantagens e quais as desvantagens do contexto digital externo à sala de aula no ensino do idioma.

No que concerne às vantagens, a principal ideia levantada nos discursos dos professores de línguas adicionais é a praticidade do contato dos alunos com a língua estrangeira, o que facilita não somente a aquisição da língua, mas também a vivência da cultura na qual o idioma está inserido. Isso pode ser observado na SD1: "o aluno tem 
uso prático do idioma, pois muitos iniciam o curso de uma língua estrangeira, mas não tem onde e com quem colocá-la em prática. [...] eles ouvem e treinam o idioma facilitando assim o processo auditivo e a aprendizagem em si” (PA-2); e na SD2: “imersão mais fácil no idioma através do acesso de elementos culturais ligados à língua estudada. Acesso a informações de modo mais ágil - conteúdos, explicações, exercícios -, o que propicia uma independência maior nos estudos" (PE-1).

$\mathrm{Na} \mathrm{AD}$ os sentidos se caracterizam pelo deslocamento, pelo deslize de sentido(s), afinal, derivam de outras significações. Para Foucault (2017, p. 146), a análise dos enunciados "repousa no princípio de que nem tudo é sempre dito [...] estudam-se os enunciados no limite que os separa do que não está dito, na instância que os faz surgirem à exclusão de todos os outros". O deslize é visto como acontecimento que não pode ser esgotado inteiramente, pois está articulado à memória e ao acontecimento, e está amarrado a enunciados anteriores e seguintes (FOUCAULT, 2017). Nesse sentido, é interessante notar que a PA-2 entende o contexto digital como forma de uso prático do idioma para o aluno e a PE-1 julga ser uma forma mais fácil de acessar o idioma, assim, o não-dito nesse discurso estabelece o deslize de sentido de que, muitas vezes, a sala de aula não se constitui como espaço de aprendizado e de uso prático do idioma, sem aspectos mais reais e mais úteis na vida do aluno, sendo, consequentemente, uma forma mais difícil de aprendizado da língua.

De acordo com Rodrigues et al. (2017), os recursos tecnológicos no ensino de línguas adicionais possibilitam ao professor utilizar materiais autênticos e inovadores, indo além da restrição do livro didático impresso, sendo esta uma vantagem da era digital, como abordado na SD3, pois: "o fácil acesso a materiais extras ajudam no melhor entendimento do conteúdo e até aproximam a cultura da Língua Inglesa dos alunos" (PI-2). Além de dinamizar a aula, a utilização dos recursos tecnológicos também se apresenta como um fator desafiador, pois, como vemos na SD4: "crianças e jovens apreciam os desafios, novidades em se tratando de tecnologia" (PA-1). Os denominados desafios e fácil acesso a materiais digitais mencionados pela PI-2 e pela PA-1 podem ser explorados de modo a instigar a autonomia do aluno no seu próprio aprendizado, como apontado por Berbel (2011, p. 37) que diz que isso: 
Além disso, é preciso refletir sobre o criticismo que deve ser mobilizado pelos professores ao utilizar o contexto digital, principalmente devido às ideologias que circulam nesse espaço. Nesse sentido, não há discurso sem sujeito e não há sujeito sem ideologia (ORLANDI, 2015). O sujeito discursivo é pensado como "posição" entre outras, ou seja, é um lugar que o sujeito ocupa para dizer. Assim, é preciso refletir sobre as posições envolvidas dentro desses espaços digitais para que não tornem os sujeitos envolvidos em sujeitos submissos.

Por outro lado, os professores entrevistados consideram que o contexto digital apresenta algumas desvantagens para o ensino de línguas adicionais para adolescentes, principalmente relacionadas ao manuseio das tecnologias e recursos disponibilizados online. Como aponta Lévy (1999), o espaço cibercultural é minado por infinitas informações provenientes da interconexão de rede de computadores em nível global; deve-se a essa imensa quantidade de informações, a necessidade de um olhar crítico sobre seu conteúdo. Nesse mesmo sentido, os professores percebem a grande quantidade de informações disponíveis e a falta de maturidade dos alunos em selecionarem esses conteúdos, como exposto na SD5: "o excesso de informações pode resultar em dificuldade de seleção do que é realmente útil ou não" (PE-1); na SD6: "há, talvez, uma falta de maturidade e apuração nos olhos deles (os alunos) para entender como melhor aproveitar cada ferramenta" (PF-2); e na SD7: "o contexto digital pode dispersar muito a atenção dos jovens" (PI-2). Ademais,

[...] é preciso ter claro e acrescentar, ainda, que a tecnologia por si só não é capaz de fomentar e melhorar a qualidade do ensino. Os participantes envolvidos nesse processo educacional são primordiais para melhorar sua própria aprendizagem e ensino mediado por esses dispositivos já que o contato com línguas estrangeiras é para que haja a comunicação entre pessoas. (CARVALHO, 2020, p. 91)

Nesse sentido, também ressaltamos a importância da presença do professor no processo de ensino, como sendo uma figura indispensável, como destaca a SD8: "por mais aplicativos que existam, nenhum deles substitui a presença física do professor" (PE-2). Sobre isso, Berbel (2011) ressalta que uma boa interação entre professores e alunos contribui para a motivação dos alunos no aprendizado do idioma, pois "facilita a identificação pessoal com aquilo que ele apresenta em sala de aula, possibilitando a valorização das atividades e conteúdos propostos e a internalização das exigências ou 
demandas externas” (BERBEL, 2011, p. 37). Desse modo, o professor não é mais visto como detentor do conhecimento, mas como um intermediário desse processo.

Com base nos discursos dos entrevistados, percebemos que as vantagens do contexto digital no processo de aprendizagem de línguas adicionais são mais relevantes perante as desvantagens apontadas. Entretanto, as desvantagens podem e devem ser estudadas pelos professores, pelos representantes das instituições de ensino e pelos alunos e seus respectivos responsáveis, para que juntos encontrem maneiras de superar essas adversidades.

Por meio do aporte teórico-metodológico na $\mathrm{AD}$, levamos em consideração o que Foucault (2017) discute sobre o não dito nos discursos. Observamos que, a partir da realidade específica desses participantes, talvez algumas dificuldades que afetam outras localidades brasileiras não são vivenciadas por eles, como dificuldade de acesso à internet, por exemplo. Ademais, as posições sócio históricas que os entrevistados desempenham são inúmeras e, portanto, influenciam seus modos de perceber e de falar sobre o tema. Dito de outro modo, o discurso desses participantes está condicionado à posição-sujeito que ocupam; esses discursos poderiam ser diferentes se pensarmos, por exemplo, em outras regiões do país.

\subsection{Utilização de Recursos Digitais e Indicações}

Incorporada ao questionário, uma pergunta direcionada aos professores de línguas adicionais foi sobre a utilização de ferramentas tecnológicas em sala de aula. A pesquisa revelou que todos os professores, independentemente do âmbito escolar onde atuam, utilizam-se de recursos digitais para o desenvolvimento de suas aulas. Ressaltamos que os participantes pertencem à realidade da região Oeste de Santa Catarina, região sul do Brasil e que, segundo dados do IBGE (BRASIL, 2018), em torno de $81,1 \%$ dos domicílios tinham acesso à internet, facilitando assim, a utilização de recursos digitais no âmbito escolar.

Dentre os recursos elencados pelos participantes, podemos citar, através da SD9: "filmes, séries, músicas e jogos" (PI-1); da SD10: "vídeos no Youtube, músicas e aplicativos” (PF-1); da SD11: “(...) vídeos curtos, "memes" e jogos, como o kahoot” (PF-2); da SD12: “canais no Youtube, aplicativos, jogos, músicas, séries, sites de 
pesquisa" (PA-1); e da SD13: "YouTube, filmes, séries, da internet (lyricstrainning.com), jogos online" (PE-2). É possível perceber que a plataforma do YouTube, filmes, séries e músicas são predominantes nas práticas didáticas que envolvem o contexto digital.

Partimos dos apontamentos de Prensky (2001) de que os alunos adolescentes da atualidade fazem parte das primeiras gerações nascidas dentro do contexto cibercultural, sendo reconhecidos como nativos digitais; vemos, de outra parte, professores que não nasceram inseridos em meio tecnológico, mas que em certo ponto se viram envolvidos pelas novas tecnologias e seus usos, são estes os "imigrantes digitais" (PRENSKY, 2001, p. 2). Diante disso, reconhecemos uma tendência configurada pela utilização das novas tecnologias no ensino, por parte dos professores, buscando atender as demandas dos grupos atuais de aprendizes adolescentes. $\mathrm{O}$ discurso dos professores denota uma concordância com esse aspecto do processo de ensino, posto que a utilização desses recursos digitais em aulas vai além da busca por conteúdo diferenciado e dinâmico: professores buscam o enriquecimento de suas práticas pedagógicas e uma experimentação mais rica para o processo de aprendizagem dos alunos. Nessa proposta, evidenciam-se a SD14: “(...) uso com frequência um canal alemão que oferece áudios, vídeos, programas de televisão, pensados para estudantes do idioma [...]. Aplicativos e jogos eu normalmente tenho e procuro aqueles que combinam com o perfil de cada aluno" (PA-2); e a SD15: "geralmente utilizo músicas para trabalhar alguma estrutura gramatical. Os vídeos para mostrar algum aspecto cultural, [...] Filmes e séries mais como recomendação. Às vezes proponho algum cine-debate" (PE-1).

Quando questionados sobre as razões pelas quais fazem indicações de ferramentas digitais para o estudo da língua-alvo, os professores elencaram, de forma geral, a importância do contato com o idioma, como mencionado na SD16: "indico aplicativos que possam ajudar e facilitar o aprendizado de acordo com a necessidade de cada aluno ou turma. Reforço a importância de manter contato com o idioma [...], seja ouvindo músicas, assistindo séries, filmes e/ou jogando" (PI-1); e na SD17: "quanto mais houver estudos externos, melhor será a aprendizagem da língua estrangeira" (PE2); além da importância da diversificação de estímulos na aprendizagem da língua-alvo, posto que utilizar recursos digitais, como mencionado na SD18: "é uma maneira de contextualizar e diversificar o ensino” (PI-2); na SD19: “(...) enriquece a experiência de 
aprendizagem dos alunos" (PF-1); na SD20: "é excelente para a aprendizagem. Sem sair de casa o aluno pode ter acesso a todas as variantes do espanhol, língua a qual ensino, ao assistir séries, ver filmes, etc." (PE-1); e na SD21: "é um meio divertido e diversificado dos alunos treinarem o idioma. [...] quando seguimos apenas o material didático, o aluno não deseja ficar revendo o conteúdo para treinar, mas ouvir músicas e assistir séries ou filmes, é atrativo, portanto, pedagógico" (PA-2).

Com sentido de fechamento, a SD22 apresenta que: "o contexto digital facilitou o aprendizado e o ensino de idiomas estrangeiros por tornar o acesso muito mais fácil com várias plataformas [...], trazendo e tornando a vivência e a experiência com o idioma mais fácil e real" (PI-1). Nessa perspectiva, observamos que o contexto digital, a partir dos discursos dos participantes, proporciona aos estudantes adolescentes contato com a língua almejada de diversos modos, o que parece contribuir para o aprendizado e para a construção de conhecimentos diversos. Assim, na percepção dos entrevistados, os recursos digitais auxiliam na tarefa de ensinar do professor, mas, ao mesmo tempo, exigem maior comprometimento, tanto por parte dos aprendizes quanto por parte dos educadores.

\subsection{Percepções sobre Desempenho na Língua-Alvo}

Considerando que nem todos os alunos adolescentes fazem uso dos recursos digitais com motivação educacional e pensando em sua autonomia no processo de aprendizagem da língua-alvo, indagamos os professores sobre suas percepções relativas ao desempenho de alunos que utilizam recursos digitais para o estudo da língua. Alguns professores relatam que a simples exposição à língua-alvo contribui para o melhoramento do desempenho do aluno nas aulas, o que pode ser visto na SD23: "quanto mais frequente o contato com o idioma, maior é a possibilidade de aprendizado efetivo" (PE-1); e na SD24: "pelo fato do aluno usar mais a tecnologia, ele consequentemente estará praticando mais e obtendo um melhor desempenho" (PA-1). A respeito disso, Almeida e Ferreira (2019, p. 108) afirmam que os alunos "passam a ser capazes de combinar os usos dos recursos semióticos (linguagem, imagem, textos, vídeos, cores, formas, fontes) de outras maneiras, diferentes das pré-estabelecidas 
culturalmente" e, a a partir disso, podem (re)inventar outras relações e construções de sentidos entre língua e linguagem.

Sobre a utilização das ferramentas digitais, de acordo com as respostas obtidas, podemos relacionar o interesse pela utilização de tais recursos com o melhor desempenho em atividades que envolvam as habilidades linguísticas de compreensão e produção oral, como referido na SD25: "principalmente com a habilidade do listening e do speaking, que se dá justamente pelo fato de terem um contato maior com o idioma por meio de algo que gostam de fazer, o que facilita o aprendizado" (PI-1); na SD26: "ficam com as habilidades mais apuradas. Quanto mais exposição, mais desenvoltura (PF-2); e na SD27: “ouvindo músicas regularmente, por exemplo, já ajuda muito a treinar a audição (PE-2).

Observando a ideia central apresentada no discurso dos professores, podemos ressaltar que alunos adolescentes que utilizam as ferramentas digitais para estudo da língua-alvo apresentam um desempenho significativamente melhor em comparação ao desempenho de alunos que não fazem tal uso, como apontado na SD28: "tem maior capacidade de compreender frases usuais, sabendo quando usá-las, a capacidade auditiva também é mais aguçada do que de alunos que estão acostumados apenas a ouvir o professor e o material didático" (PA-2); e na SD29: "eles constróem mais conhecimento e vem com uma base mais consolidada para a aula" (PF-1).

Por meio desses dizeres podemos depreender uma influência positiva do contexto digital sobre o processo de ensino-aprendizagem de línguas adicionais. Ressaltamos, no entanto, que, como essa constatação não parte de testes empíricos com alunos, mas sim das percepções de professores, dificulta-se uma possível quantificação das contribuições do contexto digital no aprendizado e na desenvoltura dos alunos nas línguas adicionais. Posto que a presente pesquisa buscou realizar uma breve discussão sobre as implicações do contexto digital no ensino de línguas adicionais, analisando o discurso de professores da região Oeste de Santa Catarina, ainda outros estudos de caráter experimental-quantitativo se fazem necessários para conclusões mais assertivas acerca do tema.

\section{CONSIDERAÇÕES FINAIS}


Refletindo sobre o cenário tecnológico no qual nos vemos inseridos, a presente pesquisa, de cunho qualitativo, buscou discutir as implicações do contexto digital no ensino de línguas adicionais, uma vez que há décadas vivenciamos uma era na qual a cibercultura domina as relações e a construção do conhecimento. Ademais, analisou-se o discurso de professores, buscando observar suas perspectivas e considerações sobre o contexto digital e o ensino de línguas, além de refletir sobre vantagens e desvantagens dessa interação.

A pergunta que guiou esta investigação foi o desejo de compreender como professores de línguas adicionais, com foco no público adolescente, lidam com o contexto digital nos seus processos pedagógicos. Respondemos, ao longo do estudo, aos objetivos de realizar um levantamento teórico sobre o ensino no contexto digital; de analisar o discurso de professores no que concerne às implicações do contexto digital no ensino de línguas adicionais, elencando seus aspectos positivos e negativos; bem como investigar os impactos do contexto digital no desempenho dos alunos na língua-alvo, partindo da percepção dos professores investigados.

A partir da análise do discurso dos professores, notou-se uma grande adaptação e até mesmo uma afinidade com recursos digitais e tecnológicos durante as aulas por parte deles, facilitando a interação com o aluno e a construção do conhecimento na língua-alvo.

Já na análise dos pontos positivos e negativos da influência do contexto digital, professores ressaltaram diversas vantagens da utilização de recursos digitais para o aprendizado, como maior contato com a língua adicional, exposição a estímulos diversificados, além de um melhor desempenho na compreensão e produção da línguaalvo.

Com base nos conceitos mobilizados da área da $\mathrm{AD}$, observamos que alguns dizeres não emergem nos discursos dos professores, principalmente relacionados a dificuldades de uso e aplicação do contexto digital e falta de capacitação profissional. Refletindo sobre as desigualdades encontradas em nosso país, tratamos de uma pesquisa com recorte geográfico bem específico (região Oeste de Santa Catarina); todavia, temos conhecimento sobre as dificuldades de acessar e usar plataformas por parte dos alunos, poucos cursos de capacitação para administrar e inovar as práticas pedagógicas, falta de 
recursos físicos nos espaços escolares, entre tantos outros fatores que docentes precisam enfrentar dia a dia.

Concluímos, portanto, que investigar as práticas de ensino na era da cibercultura vem a contribuir com o melhor entendimento sobre os processos de transformação pelos quais a sociedade contemporânea vem passando. Já o processo de ensino-aprendizagem de línguas, imerso nesse contexto, demonstra-se influenciado por completo por recursos digitais e fontes diversas do saber, veiculadas entre as comunidades globais, enriquecendo a interação entre professor, aluno e língua-alvo, nutrindo-a de experiência, de conteúdo e de dinamismo.

\section{Referências}

ALMEIDA, P. V.; FERREIRA, H. M. Formação de professores de línguas: ensino e práticas digitais. Polyphonía, Goiânia, v. 30, p. 102-119, jan./jun. 2019.

ANJOS-SANTOS, L. M. dos; GAMERO, R.; GIMENEZ, T. N. Letramentos digitais, interdisciplinaridade e aprendizagem de língua inglesa por alunos do ensino médio. Trabalhos em Linguística Aplicada, Campinas, n. (53.1), p. 79-102, jan./jun. 2014.

BAUMAN, Z. O mal-estar da pós-modernidade. Rio de Janeiro: Zahar, 1998.

BERBEL, N. A. N. As metodologias ativas e a promoção da autonomia de estudantes. Semina: Ciências Sociais e Humanas, Londrina, v. 32, n. 1, p. 25-40, jan./jun. 2011.

BRASIL. Instituto Brasileiro de Geografia e Estatística (IBGE). Uso de internet, televisão e celular no Brasil. 2018. Disponível em:

https://educa.ibge.gov.br/jovens/materias-especiais/20787-uso-de-internet-televisao-ecelular-no-brasil.html. Acesso em: 05 de out. 2020.

CARVALHO, L. B. de; CARVALHO, T. L. de. Análise de Atividades em Aplicativos Móveis para a Aprendizagem de Língua Espanhola. Macabéa - Revista Eletrônica do Netlli, Crato, v. 9, n. 3, p. 386-405, 2020.

CASSIANO, R. C. G. O uso das metodologias ativas aplicadas ao ensino de Língua Inglesa: uma reflexão acerca da contribuição das Tecnologias de Informação e Comunicação na formação autônoma de aluno de língua estrangeira da Educação Básica. Trabalho de Conclusão de Curso. São Bernardo: Universidade Federal do Maranhão - UFMA, 2019.

CHAMPANGNATTE, D. M. O.; CAVALCANTI, M. A. P. Cibercultura - perspectivas conceituais, abordagens alternativas de comunicação e movimentos sociais. Revista Estud. Comun., Curitiba, v. 16, n. 41, p. 312-326, set./dez. 2015. 
FOUCAULT, M. A arqueologia do saber. 8. ed. Rio de Janeiro: Forense Universitária, 2017.

GEBRAN, M. P. Tecnologias Educacionais. Curitiba: IESDE Brasil, 2009.

KAIRALLAH, S. K. Tecnologias digitais e ensino de língua inglesa: foco na aprendizagem híbrida. CIET: EnPED, [S.I.], p. 01-06, mai. 2018.

LEVY, P. Cibercultura. São Paulo: Editora 34, 1999.

LEMOS, A. Cibercultura e Mobilidade. A Era da Conexão. Intercom - Sociedade Brasileira de Estudos Interdisciplinares da Comunicação. XXVIII Congresso Brasileiro de Ciências da Comunicação (UERJ), Rio de Janeiro, set. 2005.

MAINGUENEAU, Dominique. Novas tendências em análise do discurso. 3. ed. Campinas: Pontes - Editora da Universidade Estadual de Campinas, 1997.

Discurso e análise do discurso. 1. ed. São Paulo: Parábola Editorial, 2015.

ORLANDI, Eni P. A linguagem e seu funcionamento: As formas do discurso. 2. ed. Campinas: Pontes, 1987.

Análise de Discurso: princípios e procedimentos. 12. ed. Campinas: Pontes Editores, 2015.

PAIVA, V. L. M. O. Tecnologias digitais no ensino de línguas: passado, presente e futuro. Revista da Abralin, v. 18, n. 1, 28 ago. 2019.

PÊCHEUX, M. Semântica e discurso: uma crítica à afirmação do óbvio. Tradução: Eni Puccinelli Orlandi et al. 5. ed. Campinas, SP: Editora da Unicamp, 2014.

PRENSKY, M. Digital natives, digital immigrants. On the Horizon, v. 9, n. 5, 2001.

RODRIGUES, J.; MUENCHOW, N.; RIBAS, F. A utilização de softwares para o ensino de inglês como L2: o Edilim como ferramenta para promover a aprendizagem na sala de aula invertida. Varedas On-line, Juiz de Fora, p. 21-39, 2017.

SANTOS, Jair Ferreira dos. O que é pós-moderno. São Paulo: Brasiliense, 2012. 